\title{
Tricuspid valve prolapse
}

INSERM

\section{Source}

INSERM. (1999). Orphanet: an online rare disease and orphan drug data base. Tricuspid valve prolapse. ORPHA:95458

A rare, congenital, non-syndromic heart malformation characterized by bulking of tricuspid valve into the right atrium during systole. It can be isolated, but is more often associated with mitral valve prolapse or with other cardiac and lung diseases. Clinical presentation depends on severity and associated findings and there is a high incidence of cardiac arrhythmias and possible bacterial endocarditis. 